\title{
Uptake of Indosol Dark-blue GL dye from aqueous solution by water hyacinth roots powder: adsorption and desorption study
}

\author{
Md. M. R. Khan • M. Z. B. Mukhlish • \\ M. S. I. Mazumder • K. Ferdous • D. M. R. Prasad • \\ Z. Hassan
}

Received: 9 July 2011/Revised: 23 December 2012/ Accepted: 10 April 2013/Published online: 14 November 2013

(C) Islamic Azad University (IAU) 2013

\begin{abstract}
Adsorption characteristics of water hyacinth roots powder for the removal of Indosol Dark-blue GL dye were investigated in batch mode. Operating variables, such as initial solution $\mathrm{pH}$, presence of detergent, adsorbent dosage, initial concentration and contact time, were studied. The results showed that the adsorption of dye increased with increasing the initial concentration and contact time. The adsorption is highly $\mathrm{pH}$ dependent and adsorption capacity increased with decrease in $\mathrm{pH}$. Kinetic study revealed that the uptake of Indosol Dark-blue GL was very rapid within the first $15 \mathrm{~min}$ and equilibrium time was independent of initial concentration. Batch equilibrium experiments were carried out at different $\mathrm{pH}$ and found that equilibrium data fitted well to Langmuir isotherm model. The maximum sorption capacity of the adsorbent was found as $86 \mathrm{mg} \mathrm{g}^{-1}$ at $\mathrm{pH} 3$ which reduced to $64 \mathrm{mg} \mathrm{g}^{-1}$ at $\mathrm{pH}$ 5. The presence of detergent reduced the sorption capacity of the adsorbent significantly. Using equilibrium and kinetic data, the forward and backward rate constants
\end{abstract}

Md. M. R. Khan ( $₫)$ · M. Z. B. Mukhlish · M. S. I. Mazumder Department of Chemical Engineering and Polymer Science, Shahjalal University of Science and Technology,

Sylhet 3114, Bangladesh

e-mail: mrkhancep@yahoo.com

K. Ferdous

Centre for Environmental Process Engineering, Shahjalal

University of Science and Technology, Sylhet 3114, Bangladesh

D. M. R. Prasad

Faculty of Chemical and Natural Resources Engineering, Universiti Malaysia Pahang, Gambang, 26300 Kuantan, Pahang, Malaysia

Z. Hassan

Faculty of Chemical Engineering, Universiti Teknologi MARA, 40450 Shah Alam, Selangor, Malaysia were determined from the unified approach model. Desorption study revealed that the dye can be recovered by swing the $\mathrm{pH}$ from low to high.

Keywords Water hyacinth roots powder - Langmuir model · Unified approach model · Detergent - Indosol Dark-blue GL

\section{Introduction}

Various industries such as textiles, leather, printing, paper and plastics extensively use dyes in order to color their products. Most of the dyes used for industrial purposes are synthetic compounds with complex aromatic molecular structures, which make them resistant to light, heat and oxidizing agents, non-biodegradable and toxic to life, with carcinogenic and mutagenic effects (Noroozi et al. 2007). The presence of very low concentrations of dyes $(<1$ $\mathrm{mg} \mathrm{L}^{-1}$ ) in the effluent is highly visible and is considered undesirable. Bangladesh having around thousands of textile factories mostly situated near big cities produces huge amount of dye containing wastewater which is being drained into the rivers. A recent survey showed that the aquatic environment of the rivers (e.g., Buriganga, Karnafully, etc.) is in the worst situation (Mozumder et al. 2008). The best way to keep our surface water healthy is to treat the effluents and make them less hazardous before discharging into water stream. In Bangladesh, only few factories have effective effluent treatment plant. The government of this country has therefore decided not to allow any textile factory without proper effluent treatment plant (ETP), which is under implementation stage. Reactive dyes are the most problematic compared to other form of dyes (Vandevivere et al. 1998; Geethakarthi and Phanikumar 
2011). Removal of these dyes from wastewater is a major environmental challenge, and there is a constant need to have an effective process that can efficiently remove these dyes. Several methods have been employed to remove dye from industrial effluent, such as biological and chemical oxidation, coagulation-flocculation, foam flotation, electrolysis, biodegradation, advanced oxidation, photocatalysis, ozonation (Vandevivere et al. 1998; Robinson et al. 2001; Papic et al. 2004; Forgacs et al. 2005; Rahbar et al. 2006; Sundrarajan et al. 2007). Many of these methods have certain merits but require considerable operational costs (Vandevivere et al. 1998; Allen and Koumanova 2005). Adsorption has been found to be a superior technique compared to other methods of wastewater treatment in terms of cost, simplicity of design and operation, availability, effectiveness and their insensitivity to toxic substances (Meshko et al. 2001; Sarma and Bhattacharyya 2005; Özcan et al. 2006). It is obvious that choice of adsorbent plays a very important role. Granular activated carbon (GAC) is widely used as an adsorbent and favorite for removal of many dyes and other pollutants (Sarma and Bhattacharyya 2004; Özcan et al. 2006). The advantages of GAC are its high surface area and higher adsorption capacity (Özcan et al. 2006; Gueu et al. 2007), but it is cost prohibitive and both regeneration and disposal of used carbon are not straightforward (McKey 1979; Sarma and Bhattacharyya 2004, 2005; Abdel-Ghani et al. 2007). This has necessitated development of low-cost materials for use as adsorbents. Natural materials or the wastes, by-products of industries or synthetically prepared materials, which are cheap and can be used as such or after some minor treatment as adsorbents, are generally called low-cost adsorbents. Among natural materials Posidonia oceanica leaf (Ncibi et al. 2007; Igwe et al. 2008), burnt clay (Mumin et al. 2007), tendu waste (Nagda and Ghole 2009), banana peel, orange peel, bagasse pith, rice husk, sawdust, etc., have been shown to give satisfactory results in removal of commercial dyes from aqueous solution (Gupta and Suhas 2009; Ozcan and Ozcan 2004). In Bangladesh, water hyacinth has no competitive use and is considered to be an undesirable species on inland waterways. The purposes of the present work are, to evaluate the adsorption potential of water hyacinth roots (WHR) powder for the removal of textile dye Indosol Dark-blue GL from aqueous solution, to determine the kinetic and equilibrium batch adsorption parameters and to predict the adsorption and desorption mechanism. Water hyacinth is selected due to its abundant availability, very low cost, biodegradability and ease of disposing without expensive regeneration.

Date and location of the research:

The research work had been carried out in Shahjalal University of Science and Technology, Bangladesh, in collaboration with Universiti Malaysia Pahang, Malaysia, from July 2009 to January 2011.

\section{Materials and methods}

Reagents and adsorbent

All chemicals used in this study were of analytical grade and were used without further purification. The dye Indosol Dark-blue GL made by Clariant, India, was kindly given by a local textile industry (Standard Group, Bangladesh). $\mathrm{NaOH}$ and $\mathrm{HCl}$ were purchased from Merk, Germany. Stock solution of the dye Indosol Dark-blue GL was prepared in distilled water, and all working solutions were obtained by appropriate dilution. Water hyacinth roots (WHR) were collected from local pond and thoroughly washed for several times to remove dirt and earthy materials followed by boiling in water for $30 \mathrm{~min}$. Afterward they were soaked in $0.1 \mathrm{M} \mathrm{HCl}$ for $20 \mathrm{~min}$ and again washed by distilled water. The roots were then dried in oven at $90-100{ }^{\circ} \mathrm{C}$ for $8 \mathrm{~h}$. The dried roots were ground and the powder thus obtained was used as adsorbent. Particle size of the adsorbent samples used for the experiments was in the range of $0.15-0.25 \mathrm{~mm}$.

Sample analysis and treatment methods

To study the effects of important parameters like $\mathrm{pH}$, adsorbent mass, initial concentration, contact time and presence of detergent on the adsorptive removal of Indosol Dark-blue GL, batch experiments were conducted at $26 \pm 2{ }^{\circ} \mathrm{C}$. For each set of experimental run, $100 \mathrm{~mL}$ of dye solution of known concentration and a pre-weighed amount of adsorbent were taken in 250-mL stopper conical flask and were agitated using a flash-shaker (Sutrat Scientific Co. Ltd. Model SF1, UK) at constant oscillation of 450 osc $\min ^{-1}$. Samples were withdrawn at appropriate time intervals and were centrifuged and final concentration of dye in the solution was determined by UV-spectrophotometer (UV-spectrophotometer, Model: UV-1650 PC, Shimadzu, Japan) at a wavelength of $587 \mathrm{~nm}$ where maximum absorbance was observed. The effect of $\mathrm{pH}$ on Indosol Dark-blue GL adsorption onto WHR was analyzed over the $\mathrm{pH}$ range from 2 to 8 . The $\mathrm{pH}$ was adjusted by addition of aqueous solution of $\mathrm{HCl}$ or $\mathrm{NaOH}(0.1 \mathrm{M})$. The effect of adsorbent dosages on dye removal was studied in the range of $2.5-20 \mathrm{~g} \mathrm{~L}^{-1}$ in $100 \mathrm{mg} \mathrm{L}^{-1}$ dye solution. The adsorption kinetic tests were performed for the initial concentration range $50-150 \mathrm{mg} \mathrm{L}^{-1}$ and adsorbent dosage of $1 \mathrm{~g}$ at $\mathrm{pH} 3$ and 4 . The adsorption capacity defined as the amount of Dark-blue GL adsorbed per unit weight of 
adsorbent $(\mathrm{WH})$ at time $t, q_{t}$ (mg dye/g adsorbent), was calculated by the following equation:

$q_{t}=\frac{\left(C_{0}-C_{t}\right) V}{W}$

where $C_{0}$ and $C_{t}\left(\mathrm{mg} \mathrm{L}^{-1}\right)$ are the liquid-phase concentrations of the dye solution at initial and at any time $t$, respectively; $V$ is the volume of the solution (L) and $W$ is the mass of dry adsorbent used (g). For adsorption isotherm tests, $100 \mathrm{~mL}$ of Indosol Dark-blue GL solution of different initial concentrations $50-150 \mathrm{mg} \mathrm{L}^{-1}$ was mixed with $1 \mathrm{~g}$ of adsorbent and agitated for $7 \mathrm{~h}$ till the equilibrium was attained. The amount of adsorption at equilibrium, $q_{e}$ (mg g ${ }^{-1}$ ) was calculated by Eq. (1); where $C_{t}$ was replaced by $C_{e}$, the liquid-phase concentration at equilibrium. Equilibrium experiments were also repeated in the presence of different amount of detergent collected from local market.

\section{Results and discussion}

Effect of adsorbent dosage

Figure 1 represents the effect of varying adsorbent dosage on the amount of dye adsorption from water hyacinth rootsDark-blue GL system. From Fig. 1, it is observed that the removal efficiency of the dye increases with increasing adsorbent dose. That is the removal efficiency increases from 8.83 to $71 \%$ with an increase in adsorbent dosage from 2.5 to $20 \mathrm{~g} \mathrm{~L}^{-1}$. This is due to the fact that by increasing adsorbent dosage, number of active site for the sorption also increases. Consequently, the more the adsorbent dosage, the more the volume of effluent that a fixed mass of water hyacinth can purify. It is also found

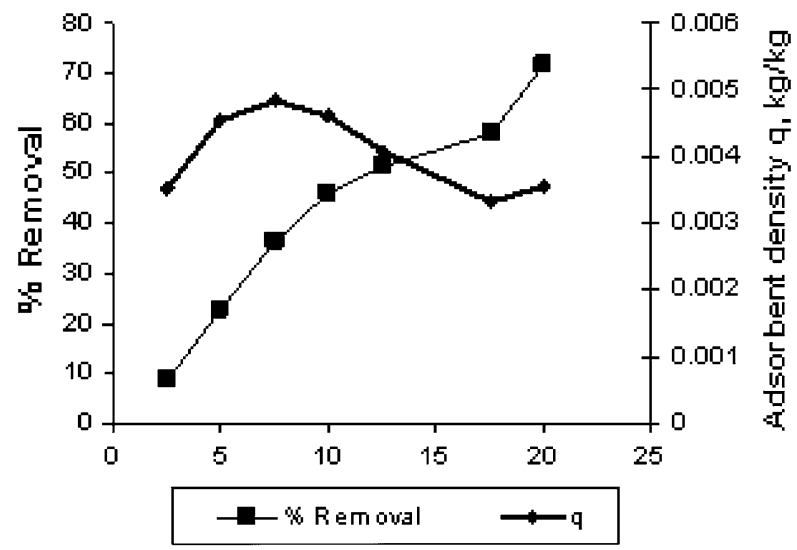

Fig. 1 Effect of adsorbent dosage on Indosol Dark-blue GL sorption onto water hyacinth roots powder (initial dye concentration $C_{0}=100 \mathrm{mg} \mathrm{L}^{-1}$; contact time $t=1 \mathrm{~h}$; volume of solution $V=100 \mathrm{~mL}$; speed of shaking $=450 \mathrm{osc} \min ^{-1} ; T=26 \pm 2{ }^{\circ} \mathrm{C}$ ) that the adsorption capacity increases from 3.5 to $4.8 \mathrm{mg} \mathrm{g}^{-1}$ for an increase in adsorbent dosage from 2.5 to $7.5 \mathrm{~g} \mathrm{~L}^{-1}$ and with further increase in adsorbent dosage from 10 to $17.5 \mathrm{~g} \mathrm{~L}^{-1}$, the adsorption capacity starts to decrease. The decrease in adsorption capacity $\left(\mathrm{mg} \mathrm{g}^{-1}\right)$ with an increase in adsorbent dosage is due to the split in the flux or the concentration gradient between solute concentration in the solution and the solute concentration on the surface of the adsorbent. Thus, with an increase in adsorbent dosage, the amount of dye adsorbed onto unit weight of adsorbent gets reduced causing a decrease in $q$ value. Similar behavior has been reported in case of adsorption of Congo Red (Rajamohan 2009) and phenol (Uddin et al. 2008) onto water hyacinth root.

Point of zero charge $\left(\mathrm{pH}_{\mathrm{PZC}}\right)$ of the adsorbent

The surface charge $Q$ of the adsorbent was calculated from the experimental titration data according to the following equation (Kiefer et al. 1997):

$Q=\frac{\left(C_{A}-C_{B}-\left[H^{+}\right]-\left[O H^{-}\right]\right)}{w}$

where $w$ is the dry weight of adsorbent in aqueous system $\left(\mathrm{g} \mathrm{L}^{-1}\right) ; C_{A}$ is the concentration of added acid in aqueous system $\left(\mathrm{mol} \mathrm{L}^{-1}\right) ; C_{B}$ is the concentration of added base in aqueous system $\left(\mathrm{mol} \mathrm{L}^{-1}\right)$; $\left[\mathrm{H}^{+}\right]$is the concentration of $\mathrm{H}^{+}$ $\left(\mathrm{mol} \mathrm{L}{ }^{-1}\right) ;\left[\mathrm{OH}^{-}\right]$is the concentration of $\mathrm{OH}^{-}\left(\mathrm{mol} \mathrm{L}^{-1}\right)$. The $\mathrm{pH}$ value at the point of zero charge was then determined by plotting $Q$ versus $\mathrm{pH}$. Figure 2 shows the surface charge of the adsorbent as a function of $\mathrm{pH}$. The point of zero charge $\left(\mathrm{pH}_{\mathrm{PZC}}\right)$ of the adsorbent (WHR) is estimated to be $5.8 \pm 0.1$. Hasan et al. (2010) reported the $\mathrm{pH}_{\mathrm{PZC}}$ of water hyacinth stem and leaves adsorbent as 4.2. Singha and Das (2012) obtained the value of $\mathrm{pH}_{\mathrm{PZC}} 6.59$ for water hyacinth roots which is in good agreement with that presented in Fig. 2. At $\mathrm{pH}<\mathrm{pH}_{\mathrm{PZC}}$, the adsorbent surface is charged positively while at $\mathrm{pH}>\mathrm{pH}_{\mathrm{PZC}}$ the surface is negatively charged. Water hyacinth root surface contains carboxylic acid group $(-\mathrm{COOH})$ and sulfonic acid group $\left(-\mathrm{SO}_{3} \mathrm{H}\right)$ (Kelley et al. 2000; Osman et al. 2010; Singha et al. 2011; Singha and Das 2012). The adsorbent surface

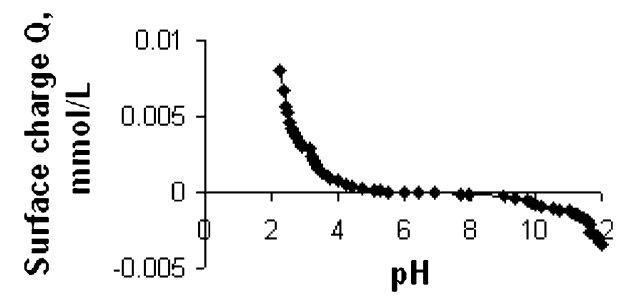

Fig. 2 Variation of surface charge of water hyacinth roots powder with system $\mathrm{pH}$ (dry weight of adsorbent in aqueous system $=2 \mathrm{~g} \mathrm{~L}^{-1}$ ) 


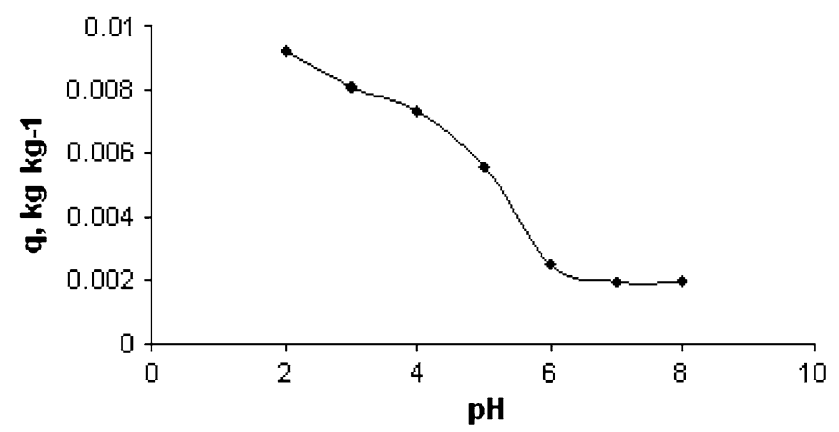

Fig. 3 Effect of $\mathrm{pH}$ on Indosol Dark-blue GL adsorption onto water hyacinth roots powder $\left(C_{0}=100 \mathrm{mg} \mathrm{L}^{-1} ; W=1 \mathrm{~g} ; V=100 \mathrm{~mL}\right.$; speed of shaking $=450 \mathrm{osc} \min ^{-1} ; \quad$ contact time $=7 \mathrm{~h}$; $\left.T=26 \pm 2{ }^{\circ} \mathrm{C}\right)$

may become positively charged due to the adsorption of $\mathrm{H}^{+}$ ion at $\mathrm{pH}<\mathrm{pH}_{\mathrm{PZC}}$ as per Eqs. (3) and (4):

$$
\begin{aligned}
& (\text { WHR })-\mathrm{COOH}+\mathrm{H}^{+}=(\text {WHR })-\mathrm{COOH}_{2}^{+} \\
& (\text {WHR })-\mathrm{SO}_{3} \mathrm{H}+\mathrm{H}^{+}=(\text {WHR })-\mathrm{SO}_{3} \mathrm{H}_{2}^{+}
\end{aligned}
$$

At $\mathrm{pH}>\mathrm{pH}_{\mathrm{PZC}}$, the surface of the adsorbent may get negatively charged as shown in Eqs. (5) and (6):

$($ WHR $)-\mathrm{COOH}+\mathrm{OH}^{-}=($WHR $)-\mathrm{COO}^{-}+\mathrm{H}_{2} \mathrm{O}$

$($ WHR $)-\mathrm{SO}_{3} \mathrm{H}+\mathrm{OH}^{-}=($WHR $)-\mathrm{SO}_{3}^{-}+\mathrm{H}_{2} \mathrm{O}$

\section{Effect of $\mathrm{pH}$}

The results of Indosol Dark-blue GL sorption onto water hyacinth roots powder at different solution $\mathrm{pH}$ are represented in Fig. 3. Adsorption of dye is found to be influenced by the solution $\mathrm{pH}$. From Fig. 3, it is observed that the adsorption capacity decreases with increasing $\mathrm{pH}$ of dye solution. By increasing the $\mathrm{pH}$ from 2 to 8 , the adsorption capacity decreases sharply from 9.26 to $1.95 \mathrm{mg} \mathrm{g}^{-1}$. The adsorption is found to be appreciable in the $\mathrm{pH}$ range from 2 to 5 . The positively charged adsorbent surface and higher adsorption capacity at lower $\mathrm{pH}\left(<\mathrm{pH} \mathrm{PZC}_{\mathrm{C}}\right)$ suggest that the dye Indosol Dark-blue GL becomes negatively charged in the solution. Adsorption occurs due to electrostatic attraction between positively charged adsorbent surface and dye anion at $\mathrm{pH}<\mathrm{pH}_{\mathrm{PZC}}$. The possible mechanism may be represented by the Eqs. (7) and (8). The high positive charge density of adsorbent surface causes enhanced adsorption at $\mathrm{pH}<5$. Negligible adsorption found at $\mathrm{pH}>\mathrm{pH}_{\mathrm{PZC}}$ may be due to weak physical force such van der Waals attraction. Therefore, it is most likely that, in addition to electrostatic force of attraction, physical force of attraction also plays a role in the present adsorption process.

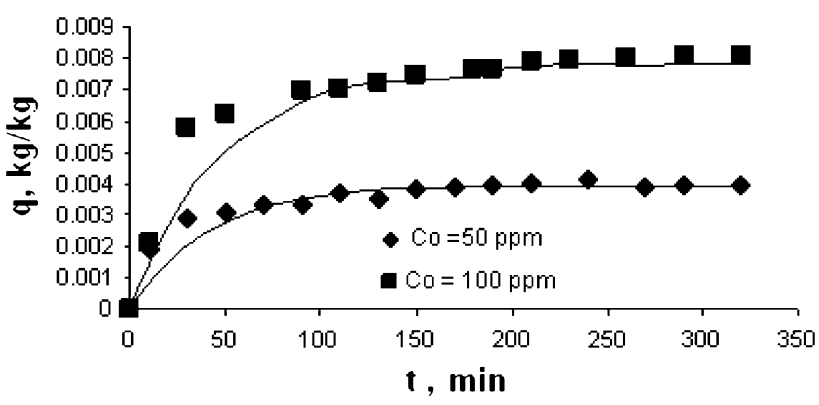

Fig. 4 Indosol Dark-blue GL adsorption $(q)$ versus adsorption time $(t)$ for different initial concentrations at $\mathrm{pH} 3$. The points are experimental values and the dense lines are for theoretical values calculated from Eq. (14) $\left(C_{0}=(50,100) \mathrm{ppm} ; W=2 \mathrm{gm}\right.$; $V=200 \mathrm{~mL} ; \quad t=5.53 \mathrm{~h} ; \quad$ speed of shaking $=450 \mathrm{osc} \mathrm{min}^{-1}$; $\left.T=26 \pm 2{ }^{\circ} \mathrm{C}\right)$

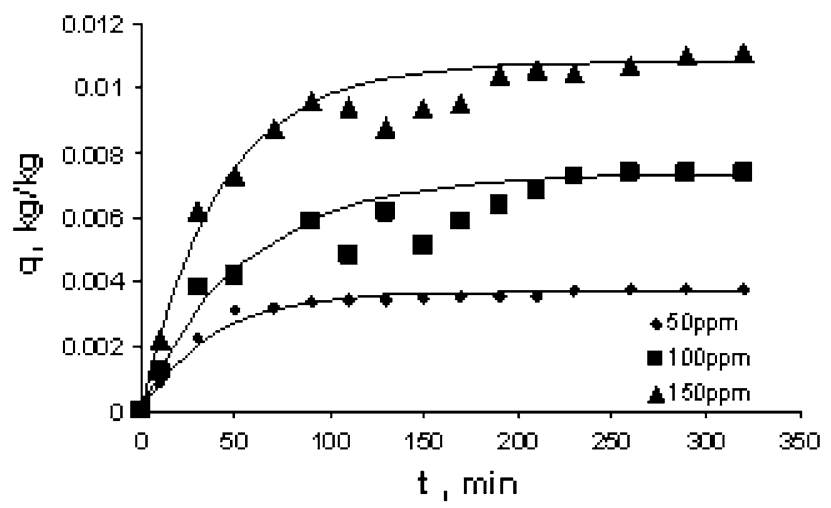

Fig. 5 Indosol Dark-blue GL adsorption $(q)$ versus adsorption time $(t)$ for different initial concentrations at $\mathrm{pH}$ 4. The points are experimental values and the dense lines are for theoretical values calculated from Eq. (14) $\left(C_{\mathrm{o}}=(50,100\right.$ and 150$) \mathrm{ppm} ; W=2 \mathrm{gm}$; $V=200 \mathrm{~mL} ; t=5.53 \mathrm{~h} ;$ speed of shaking $=450$ osc $\min ^{-1}$; $\left.T=26 \pm 2{ }^{\circ} \mathrm{C}\right)$

$$
\begin{aligned}
(\text { WHR })-\mathrm{COOH}_{2}^{+}+(\text {dye })^{-}= & (\text {WHR }) \\
& -\mathrm{COOH}_{2}^{+} \ldots(\text { dye })^{-} \\
(\mathrm{WHR})-\mathrm{SO}_{3} \mathrm{H}_{2}^{+}+(\text {dye })^{-}= & (\mathrm{WHR}) \\
& -\mathrm{SO}_{3} \mathrm{H}_{2}^{+} \ldots(\text { dye })^{-}
\end{aligned}
$$

Effects of concentration and contact time

Figures 4 and 5 represent the adsorption of dye as a function contact time for different initial concentrations (50-100 ppm) at pH 3 and 4, respectively. More than $50 \%$ of dye is removed at initial 10-15 min of adsorption, and thereafter, the rate decreases gradually leading to equilibrium. Figures 4 and 5 also reveal that adsorption capacity increases with increasing initial dye concentration. This is due to the fact that by increasing the concentration of dye 


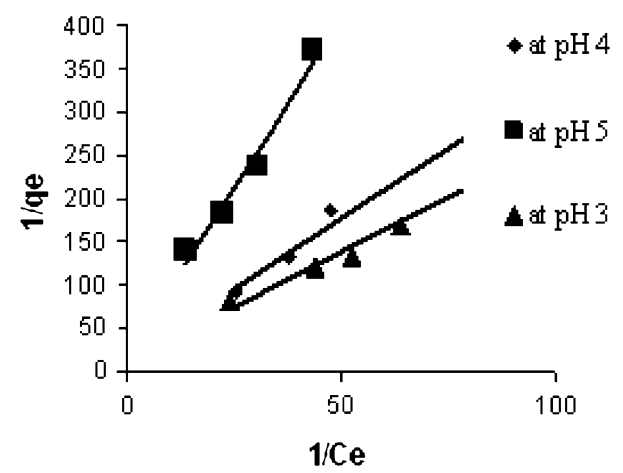

Fig. 6 Langmuir isotherm for Indosol Dark-blue GL adsorption onto water hyacinth roots powder at different $\mathrm{pH}(3-5)\left(C_{0}=(50,75,100\right.$, $125,150) \mathrm{ppm} ; W=1 \mathrm{gm} ; V=100 \mathrm{~mL}$; time of shaking $=7 \mathrm{~h}$; $\left.T=26 \pm 2{ }^{\circ} \mathrm{C}\right)$

in solution, the availability of dye molecules at the adsorbent interface also increases, thus enhancing the amount of adsorption. When the surface active sites of adsorbent are covered fully, the extent of adsorption reaches a limit resulting in saturated adsorption.

\section{Adsorption isotherm}

The experimental equilibrium data of dye adsorption on water hyacinth were fitted with Langmuir isotherm model. Langmuir isotherm assumes monolayer adsorption onto a surface containing a finite number of identical sites which are homogeneously distributed over the adsorbent surface. The linear form of Langmuir isotherm (McKay 1981) can be represented by the following equation:

$\frac{1}{q_{e}}=\frac{1}{\left(K q_{\alpha} C e\right)}+\frac{1}{q_{e}}$

where $q_{e}$ is the adsorption capacity (mg adsorbed/g adsorbent) at equilibrium; $q_{\alpha}$ is the maximum adsorption capacity ( $\mathrm{mg}$ adsorbed/g adsorbent), $C_{e}$ is the equilibrium concentration of the solution, $K$ is the adsorption equilibrium constant.

The plots of $1 / q_{e}$ versus $1 / C_{e}$ for Dark-blue $\mathrm{GL}$ adsorption on water hyacinth at different $\mathrm{pH}(3-5)$ are found to be linear as presented in Fig. 6. The Langmuir isotherm model parameters $\left(q_{\alpha}\right.$ and $\left.K\right)$ are calculated from the slope and intercept of the plots and are tabulated in the Table 1. The sorption equilibrium data in the presence of detergent are also fitted to Langmuir isotherm model (Figure not shown), and Langmuir parameters are also presented in Table 1. The adsorption is well described by the Langmuir isotherm model as the equilibrium data fit to the isotherms with correlation coefficient $\left(r^{2}\right)$ values in the range of $0.95-0.98$. Table 1 shows that the maximum sorption capacity $\left(q_{\infty}\right)$ of water hyacinth for the dye is higher at lower $\mathrm{pH}$ and sorption capacity reduces significantly in the presence of detergent. The value of $q_{\infty}$ increases from 64 to $86 \mathrm{mg} \mathrm{g}^{-1}$ with a decrease in $\mathrm{pH}$ from 5 to 3 . The maximum uptake of dye onto water hyacinth at $\mathrm{pH} 4$ without detergent is $072.6 \mathrm{mg} \mathrm{g}^{-1}$ which reduces to $9.78 \mathrm{mg} \mathrm{g}^{-1}$ in the presence of detergent having concentration of $1 \mathrm{~kg} \mathrm{~m}^{-3}$. Again sorption capacity decreases with increasing detergent dose. Detergent ions in solution may occupy some of the active sites of adsorbent leading to a decrease in number of active sites available for the sorption of dye. Consequently, sorption capacity of adsorbent for the dye drops considerably. Further detergent reduces the surface tension of aqueous solution which influences dye ions to retain in solution preferably rather than sorption on adsorbent. A comparison of maximum adsorption capacity of water hyacinth roots powder adsorbent to remove dyes from aqueous solution is shown in Table 2.

\section{Adsorption kinetics}

Unified approach model was applied to analyze the adsorption kinetics. Islam et al. (2004) developed the model to characterize the adsorbent-adsorbate system using both equilibrium and kinetic concepts. The model is valid for the systems where equilibrium data fitted well with Langmuir isotherm model. It is considered that the

Table 1 Equilibrium parameters for Indosol Dark-blue GL adsorption on water hyacinth roots powder

\begin{tabular}{lllll}
\hline $\mathrm{pH}$ & $\begin{array}{l}\text { Detergent } \\
\text { dose }\left(\mathrm{kg} \mathrm{m}^{-3}\right)\end{array}$ & \multicolumn{3}{l}{ Langmuir equilibrium parameter } \\
\cline { 3 - 5 } & $q_{\infty}\left(\mathrm{mg} \mathrm{g}^{-1}\right)$ & $\mathrm{K}\left(\mathrm{L} \mathrm{g}^{-1}\right)$ & $r^{2}$ \\
\hline 5 & - & 64 & 1.9807 & 0.965 \\
4 & - & 72.6 & 4.225 & 0.98 \\
3 & - & 86 & 4.7 & 0.976 \\
4 & 1 & 9.78 & 35.75 & 0.985 \\
4 & 2 & 9.07 & 27.52 & 0.984 \\
\hline
\end{tabular}

Table 2 Comparison of maximum adsorption capacity of water hyacinth adsorbents for the sorption of dye from aqueous solutions

\begin{tabular}{lcl}
\hline Dye & $\begin{array}{l}\text { Adsorption capacity } \\
\left(\mathrm{mg} \mathrm{g}^{-1}\right)\end{array}$ & Reference \\
\hline Congo red (pH:6) & 13.4646 & Rajamohan (2009) \\
Methylene blue & 128.9 & Low et al. (1995) \\
Victoria blue & 145.4 & Low et al. (1995) \\
Indosol Dark-blue GL & 86 & This study \\
\hline
\end{tabular}


adsorption process could be described by a physicochemical interaction of the type:

$A+a c \stackrel{k_{1}}{\stackrel{\leftrightarrow}{\Leftrightarrow}} a c A, \quad K=\frac{k_{1}}{k_{2}}$

where $A, a c$ and $a c A$ represent, respectively, the adsorbate, active sites on the adsorbents and active complexes, and $k_{1}$ and $k_{2}$ represent the rate constant for adsorption, desorption, respectively. The model is given by equation:

$\frac{\mathrm{d} q}{\mathrm{~d} t}=k_{1}\left(q_{\infty}-q\right)\left(C_{0}-w_{a} q\right)-k_{2} q$

where $q$ is the amount of dye adsorbed $\left(\mathrm{kg} \mathrm{kg}^{-1}\right)$ at time $t$, $C_{0}$ is the initial concentration of dye $\left(\mathrm{kg} \mathrm{m}^{-3}\right)$ and $w_{a}$ is the adsorbent dosage $\left(\mathrm{kg}\right.$ adsorbent $\mathrm{m}^{-3}$ ). At equilibrium, the following relations hold true:

$\frac{\mathrm{d} q}{\mathrm{~d} t}=0 \quad$ and $\quad q=q_{e}=\frac{\left(C_{0}-C_{e}\right)}{w_{a}}$

where $C_{e}$ is the bulk dye concentration at equilibrium.

At equilibrium, Eq. (11) reduces to the Langmuir equation [Eq. (9)]. Solving Eq. (11) the following relation of $q$ versus $t$ is obtained:

$\frac{1}{a(\alpha-\beta)} \ln \frac{(q-\alpha) \beta}{(q-\beta) \alpha}=k_{1} t=Y$

$q=(\alpha-\beta) \frac{(\beta / \alpha) e^{(\beta-\alpha) a k_{1} t}}{(\beta / \alpha) e^{(\beta-\alpha) a k_{1} t}-1}+\beta$

with,

$$
\begin{aligned}
& \quad \alpha=\frac{b+\sqrt{b^{2}-4 c a}}{2 a}, \quad \beta=\frac{b-\sqrt{b^{2}-4 c a}}{2 a} \\
& a=w_{a}, \quad b=C_{0}+w_{a} q_{\infty}+1 / K, \& c=q_{\infty} C_{0} \\
& \text { for } t \rightarrow \infty, q=q_{e}=\beta .
\end{aligned}
$$

The calculated value of $\beta$ directly gives the value of $q_{e}$ for a given initial concentration and adsorbent dosage. The

\begin{tabular}{|c|c|c|c|}
\hline \multirow[t]{2}{*}{$\begin{array}{l}\text { Initial } \\
\text { solution } \mathrm{pH}\end{array}$} & \multirow{2}{*}{$\begin{array}{l}\text { Initial } \\
\text { concentration } \\
\mathrm{C}_{0} \times 10^{3} \\
\left(\mathrm{~kg} \mathrm{~m}^{-3}\right)\end{array}$} & \multicolumn{2}{|c|}{$\begin{array}{l}\text { Adsorption and desorption rate } \\
\text { constants }\end{array}$} \\
\hline & & $\begin{array}{l}k_{1}\left(\mathrm{~m}^{3}\right. \\
\left.\mathrm{kg}^{-1} \min ^{-1}\right)\end{array}$ & $k_{2}\left(\min ^{-1}\right)$ \\
\hline 3 & $\begin{array}{r}50 \\
100\end{array}$ & $0.0211 \pm 0.0017$ & $0.0045 \pm 0.0004$ \\
\hline 4 & $\begin{array}{r}50 \\
100 \\
150\end{array}$ & $0.0235 \pm 0.0045$ & $0.0056 \pm 0.001$ \\
\hline
\end{tabular}

Table 3 Unified approach model parameters for the Indosol Darkblue GL adsorption onto water hyacinth roots powder experimental kinetic data are fitted to Eq. (13), and the rate constant for the adsorption $k_{1}$ is determined from the slope of the equation. $k_{2}$ is calculated from equilibrium constant $K$ using the relation $k_{2}=\frac{k_{1}}{K}$. The $k_{1}$ and $k_{2}$ values are found to be independent of different initial concentrations. Table 3 summarizes the kinetic parameters found from unified approach model. Theoretical $q$ values at different time for different initial concentrations can be calculated from the Eq. (14) using the values of rate constants and $q_{\infty}$. In Figs. 4 and 5, the dense line represents the theoretical $q$ line and the symbols are the experimental points. It is clear that the predicted adsorption data are in good agreement with those found experimentally. Thus, it can be seen that the unified approach model describes the equilibrium and kinetics well and is useful for modeling the Indosol Dark-blue GL adsorption on to water hyacinth

\section{Desorption studies}

To explore the possibility of recovery of adsorbent and adsorbate, desorption studies were conducted with varying $\mathrm{pH}$. Initially, adsorption was performed at $\mathrm{pH} 3$ [initial concentration of dye $=100 \mathrm{mg} \mathrm{L}^{-1}$, which is used for this study (Figure not shown)]. Thereafter, desorption was carried out by varying the $\mathrm{pH}: 3-8$. Mention that at $\mathrm{pH} 3$, the concentration of dye in solution was $18.3 \mathrm{mg} \mathrm{L}^{-1}$; whereas at $\mathrm{pH} 8$, it reached to $90.13 \mathrm{mg} \mathrm{L}^{-1}$. These results were confirming that the retained dye (Indosol Dark-blue GL) molecules (onto the adsorbent) can easily be desorbed with increasing the $\mathrm{pH}$ of the solution. This desorption of dye molecules from the adsorbent surface to the solution medium may be due to the affinity of negatively charged hydroxyl ion $\left(\mathrm{OH}^{-}\right)$to the positively charged proton $\left(\mathrm{H}^{+}\right)$, which are also protonated with the $-\mathrm{COOH}$ group of adsorbents (WHR/WRH), as proposed in Eqs. (15) and (16):

$$
\begin{aligned}
& (\mathrm{WHR})-\mathrm{COOH}_{2}^{+} \ldots(\text { dye })^{-}+\mathrm{OH}^{-} \\
& \quad \rightarrow(\text { WHR })-\mathrm{COOH}+\mathrm{H}_{2} \mathrm{O}+(\text { dye })^{-} \\
& (\mathrm{WRH})-\mathrm{SO}_{3} \mathrm{H}_{2}^{+} \ldots(\text { dye })^{-} \rightarrow \\
& \quad(\mathrm{WRH})-\mathrm{SO}_{3} \mathrm{H}+\mathrm{H}_{2} \mathrm{O}+(\text { dye })^{-}
\end{aligned}
$$

\section{Conclusion}

The present investigation shows that water hyacinth roots powder can be used as adsorbent effectively for the removal of Indosol Dark-blue GL from aqueous solution. The adsorption is found to be appreciable in the $\mathrm{pH}$ range from 2 to 5. Adsorption takes place at acidic medium and in alkaline medium desorption occurs. $\mathrm{pH}_{\mathrm{PZC}}$ of water 
hyacinth root is found at $5.8 \pm 0.1$. Adsorption equilibrium is well described by the Langmuir isotherm model. The maximum adsorption capacity is estimated as $86 \mathrm{mg} \mathrm{g}^{-1}$ at $\mathrm{pH}=3$ and $\mathrm{T}=26 \pm 2{ }^{\circ} \mathrm{C}$. Using equilibrium and kinetic data, the forward and backward rate constants are determined from the unified approach model. The rate constants are found to be independent of different initial concentrations. The theoretical $q$ values predicted from the model are in good agreement with those found experimentally. The presence of detergent reduces the sorption capacity of the adsorbent significantly and sorption capacity decreases with increasing detergent dose. Therefore, it is recommended that wastewater should make detergent free before its treatment by adsorption method.

Acknowledgments This work has been funded by the Department of Chemical Engineering and Polymer Science, Shahjalal University of Science and Technology, Bangladesh. Grant: We are thankful to Universiti Malaysia Pahang for collaboration in this project.

\section{References}

Abdel-Ghani NT, Hefny M, El-Chaghaby GAF (2007) Removal of lead from aqueous solution using low cost abundantly available adsorbents. Int J Environ Sci Technol 4(1):67-73

Allen SJ, Koumanova B (2005) Decolourisation of water/wastewater using adsorption. J Univ Chem Technol Meta 40:175

Forgacs E, Cserhati T, Oros G (2005) Removal of synthetic dyes from wastewaters: a review. Environ Int 30:953-971

Geethakarthi A, Phanikumar BR (2011) Adsorption of reactive dyes from aqueous solutions by tannery sludge developed activated carbon: kinetic and equilibrium studies. Int $\mathrm{J}$ Environ Sci Technol 8(3):561-570

Gueu S, Yao B, Adouby K, Ado G (2007) Kinetics and thermodynamics study of lead adsorption on to activated carbons from coconut and seed hull of the palm tree. Int J Environ Sci Technol 4(1):11-17

Gupta VK, Suhas (2009) Application of low-cost adsorbents for dye removal: a review. J Environ Manag 90:2313-2342

Hasan HS, Ranjan D, Talat M (2010) Water hyacinth biomass (WHB) for the biosorption of hexavalent chromium: optimization of process parameters. Bioresources 5(2):563-575

Igwe JC, Abia AA, Ibeh CA (2008) Adsorption kinetics and intraparticulate diffusivities of $\mathrm{Hg}$, $\mathrm{As}$ and $\mathrm{Pb}$ ions on unmodified and thiolated coconut fiber. Int $\mathrm{J}$ Environ Sci Technol 5(1):83-92

Islam MA, Khan MR, Mozumder MSI (2004) Adsorption equilibria and adsorption kinetics: a unified approach. Chem Eng Technol 27:1095-1098

Kelley C, Curtis AJ, Uno JK, Berman CL (2000) Spectroscopic studies of the interaction of $\mathrm{Eu}(\mathrm{III})$ with the roots of water hyacinth. Water Air Soil Pollut 119:171-176
Kiefer E, Sigg L, Schosseler P (1997) Chemical and spectroscopic characterization of algae surfaces. Environ Sci Technol 31:759-764

Low KS, Lee CK, Tan KK (1995) Biosorption of basic dyes by water hyacinth roots. Bioresour Technol 52:79-83

McKay G (1981) Design models for adsorption systems in wastewater treatment. J Chem Technol Biotechnol 31:717-731

McKey G (1979) Basic dye adsorption on activated carbon. Water Air Soil Pollut 12:307

Meshko V, Markovska L, Mincheva M, Rodrigues AE (2001) Adsorption of basic dyes on granular activated carbon and natural zeolite. Water Res 35(14):3357

Mozumder MSI, Khan MR, Islam MA (2008) Kinetics and mechanism of $\mathrm{Cr}(\mathrm{VI})$ adsorption onto tea leaves waste. Asia-Pac J Chem Eng 3:452-458

Mumin MA, Khan MMR, Akhter KF, Uddin MJ (2007) Potentiality of open burnt clay as an adsorbent for the removal of Congo red from aqueous solution. Int J Environ Sci Technol 4(4):525532

Nagda GK, Ghole VS (2009) Biosorption of congo red by hydrogen peroxide treated tendu waste. Iranian J Environ Heal Sci Eng 6(3): 195-200

Ncibi NC, Mahjoub B, Seffen M (2007) Adsorptive removal of textile reactive dye using Posidonia oceanica (L.) fibrous biomass. Int J Environ Sci Technol 4(4):433-440

Noroozi B, Sorial GA, Bahrami H, Arami M (2007) Equilibrium and kinetic adsorbent-Silkworm pupa. J Hazard Mater 139:167174

Osman S, Atia F, Hakeem NA, Neklawy MMA, Fahem A (2010) Molecular spectroscopic study of water hyacinth collected from different media. Aust J Basic Appl Sci 4(12):6134-6139

Ozcan AS, Ozcan A (2004) Adsorption of acid dyes from aqueous solutions onto acid activated bentonite. J Colloid Interf Sci 286:39

Özcan A, Öncü EM, Özcan AS (2006) Kinetics, isotherm and thermodynamic studies of adsorption of Acid Blue 193 from aqueous solutions onto natural sepiolite. Colloids Surf A 277:90

Papic S, Koprivanac N, Bozic AL, Metes A (2004) Removal of some reactive dyes from synthetic wastewater by combined $\mathrm{Al}(\mathrm{III})$ coagulation/carbon adsorption process. Dyes Pigm 62:293-300

Rahbar MS, Alipour E, Sedighi RE (2006) Color removal from industrial wastewater with a novel coagulant flocculant formulation. Int J Environ Sci Technol 3(1):79-88

Rajamohan N (2009) Equilibrium studies on sorption of an anionic dye onto acid activated water hyacinth roots. Afr J Environ Sci Technol 3(11):399-404

Robinson T, McMullan G, Marchant R, Nigam P (2001) Remediation of dyes in textile effluent: a critical review on current treatment technologies with a proposed alternative. Bioresour Technol $77: 247-255$

Sarma A, Bhattacharyya KG (2004) Azadirachta indica leaf powder as an effective biosorbent for dyes: a case study with aqueous Congo Red solutions. J Environ Manag 71:217

Sarma A, Bhattacharyya KG (2005) Utilization of a biosorbent based on Azadirachta indica (Neem) leaves for removal of watersoluble dyes. Indian J Chem Technol 12:285

Singha B, Das SK (2012) Removal of Pb(II) ions from aqueous solution and industrial effluent using natural biosorbents. Environ Sci Pollut Res Int 19(6):2212-2226 
Singha B, Naiya KT, Bhattacharya AK, Das SK (2011) Cr(VI) Ions removal from aqueous solutions using natural adsorbents-FTIR studies. J Environ Prot 2:729-735

Sundrarajan M, Vishnu G, Joseph K (2007) Decolorisation of exhausted reactive dye bath using ozonator for reuse. Int $\mathbf{J}$ Environ Sci Technol 4(2):263-270
Uddin MT, Islam MS, Islam MA, Abedin MZ (2008) Uptake of phenol from aqueous solution by burned water hyacinth. Pol J Chem Technol 10(2):43-49

Vandevivere PC, Bianchi R, Verstrete W (1998) Treatment and reuse of wastewater from the textile wet-processing industry: review and emerging technologies. J Chem Tech Biotechnol 72:289-302 